

\title{
Electromagnetic Stress
}

AND

VELOCITY GAGES

\author{
R. S. Wilson
}

DEVELOPMENT DIVISION

\section{DISCLAIMER}

This report was prepared as an account of work sponsored by an agency of the United States Government. Neither the United States Government nor any agency thereof, nor any of their employees, makes any warranty, express or implied, or assumes any legal liability or responsibility for the accuracy, completeness, or usefulness of any information, apparatus, product, or process disclosed, or represents that its use would not infringe privately owned rights. Reference herein to any specific commercial product, process, or service by trade name, trademark, manufacturer, or otherwise does not necessarily constitute or imply its endorsement, recommendation, or favoring by the United States Government or any agency thereof. The views and opinions of authors expressed herein do not necessarily state or reflect those of the United States Government or any agency thereof.

July - September 1971

P. O. No. 58-0038 


\section{DISCLAMIER}

Portions of this document may be illegible in electronic image produets. Images are produced from the best available original docoment. 


\title{
ELECTROMAGNETIC STRESS
}

\author{
AND \\ VELOCITY GAges
}

\begin{abstract}
The installation of a new electromagnet to be used with the stress and velocity gages is discussed. The results obtained from a new gage designed to eliminate the anomalous signals reported last quarter are given. Using this gage, a comparison of the waveforms from the XMC 2361 driver and the MC 2453 driver subassembly was made; the difference between the two, as determined by the velocity gage, is negligible. Also reported are the results of an unsuccessful attempt to use the velocity gage to pick up a timing signal from the XMC 2361 flyer plate.
\end{abstract}

\section{DISCUSSION}

The magnet originally used for this work has been replaced by a MSI Model L-75;, 7-inch electromagnet. The larger pole faces produce a more homogeneous field which simplifies measuring the field strength and produces more accurate results. Also, this magnet does not require water cooling which simplifies the operation. The power supply provided with the magnet maintains a constant current to within $0.02 \%$, which is a considerable improvement over the previous power supply. Several shots have been fired satisfactorily in the new magnet to date.

Last quarter the results obtained from velocity gages driven by various configurations of the MC 2453 sub-assemblies were reported. To compare this driver with the XMC 2361, shots were made using the latter driver in the same setup as used last quarter with the MC 2453. Although satisfactory results were cbtained, more accurate data are now available from later shots which eliminate the ambiguity caused by the baseline offset observed with drivers using an aluminum attenuator plate between the explosive and the velocity gage.

This anomalous signal was observed when the shock wave entered the aluminum and continued until the wave reached the gage sensing element, after which time the negative signal was combined with the true particle velocity signal. It then became the effective baseline for the velocity signal and thereby prevented obtaining absolute velocity measurements.

A new sensing element configuration has been designed which separates these two signals by delaying the velocity signal until the shape of the anomalous waveform has been recorded. This new gage, designated type 13, consists of five $4 \mathrm{~mm}$ wide elements spaced along the axis of the gage at intervals of $8.9 \mathrm{~mm}$. The elements, made of 0.004-inch diameter copper wire, are wrapped around the form shown in Fig. 1 and potted into epoxy as described for previous gages. Figs. 2 and 3 show the oscilloscope traces from the first and fourth elements produced by an XMC 2361 driver. The first element was at a depth of $10.4 \mathrm{~mm}$, the same depth used with the type 9 gages, and shows the same negative signal obtained with the 
earlier gages. The fourth element, at a depth of $37.1 \mathrm{~mm}$, shows the decay of the anomalous signal before the shock wave reached this depth. This signal can be subtracted from the particle velocity signal of the first element to give the true particle velocity of the medium at the depth of the first element. The anomalous signal attenuates with distance and therefore it is necessary to multiply the amplitude of the signal from the fourth element by a constant such that it coincides with the negative signal from the first element. Shown in Fig. 4 is the pressure profile from the trace in Fig. 2 and also shown from identical shots are two of the negative signals from the fourth elements, each multiplied by the constant required to make its maximum amplitude match that of the first element's negative signal. The shape of the signals is seen to repeat quite well for these shots. When their average is subtracted from the signal of the element at 10.4 $\mathrm{mm}$, the stress waveform shown in Fig. 5 is obtained. This is considered the most accurate data obtained for the XMC 2361 driver from the velocity gage.

An identical analysis was made for the MC 2453 driver sub-assembly which, as discussed in last quarter's report, suffers from a similar negative baseline shift. The profiles shown in Figs. 6 and 7 were obtained by the same method outlined above. The conspicuous humps in the plots of Fig. 6 had previously been considered to represent a real rise in the pressure due to a reflected wave either in the driver or in the gage itself. However, this is obviously not the case as the hump is seen to occur at approximately the same time for all sensing elements, regardless of depth. It apparently represents a magnetic signal originating outside the gage since, for the elements at $37.1 \mathrm{~mm}$, it occurs before the arrival of the shock wave. The most obvious physical difference between the XMC 2361 driver and the MC 2453 sub-assembly is that the former is completely enclosed in a metal canister while the latter consists merely of a steel capsule which holds the explosive. It is possible that the hump is a signal generated by the movement of the capsule fragments through the magnetic field but that for the XMC 2361 this signal is shielded by the enclosing canister. The approximate $10 \mu \mathrm{sec}$ delay of this signal after driver break-out is, however, difficult to explain with this premise. It is reasonable to expect that the canister itself would ultimately produce a similar signal due to its motion through the magnetic field, although this has never been observed. However, if this signal. was also delayed by about $10 \mu \mathrm{sec}$ it would not be recorded because failure of the sensing element occurs before this time. In any case, the unpredictable amplitude and time of occurrence of the signal make it impossible to accurately remove it from the particle velocity signal. Therefore, the pressure profile in Fig. 7 is given for only $4 \mathrm{usec}$, the approximate time interval between the arrival of the shock wave at the first element and the occurrence of the hump. Test shots will be made using the complete MC 2453 driver, which is enclosed in a canister similar to the XMC 2361 unit, to see if this will eliminate the problem.

It was thought that the same mechanism which caused the anomalous signal from the aluminum plate could possibly be used to determine the time at which the flyer plate inside the XMC 2361 driver began to move. No attempt had previously been made to look at the gage signal early enough to see if there was such an effect. Two shots were built for this purpose using the type 9 gage. Due to a premature triggering of the oscilloscopes, however, all data from one shot were lost. For a still unknown reason, the gage signal of the second shot was superimposed on a large ( $0.3 \mathrm{v}$ ) negative signal. This caused most of the oscilloscope traces to be deflected off the screen. The one usable signal obtained is shown in Fig. 8 . 
The only new information on this signal is a slight positive shift observed from 9.5 to $4.2 \mu \mathrm{sec}$ before break-out of the shock wave from the driver (taken as the beginning of the anomalous signal). The time of the end of this signal, $4.2 \mu \mathrm{sec}$, falls within the range of times for the flyer plate as measured by other techniques. However, no explanation has been found for the $9.5 \mu$ sec pulse, and since the two are apparently related, it is likely that neither has anything to do with the flyer plate. Also, the signal is of such a small amplitude-less than $4 \mathrm{mv}$, comparable to the noise in the circuit-that accurate time measurements are difficult. Therefore, further effort to use the velocity gage to pick up a signal from the flyer plate was not considered worthwhile.

\section{FUTURE WORK; COMMENTS; CONCLUSIONS}

The problem caused by the presence of an aluminum plate between the driver and gage has been solved by the type 13 velocity gage. It is expected that it will only be necessary to make one calibration shot for any new gage-driver configuration with the type 13 gage to characterize the anomalous signal which can then be subtracted from whatever signal the new configuration produces to reveal the true particle velocity.

Shots will be made using the complete MC 2453 driver to permit a better comparison between it and the XMC 2361. It is hoped that these shots will also eliminate the hump in the MC 2453 sub-assembly signals.

A new stress gage style has been designed; the gages are presently being built and will be fired as soon as they are ready. This style was created specifically to overcome the difficulties encountered with stress gages reported last quarter. Also, a new velocity gage pattern has been made that is similar to the type 9 gage which has worked very well to date. Slight modifications were made to simplify assembly of the sensing elements. All such future gages will be of this form. 


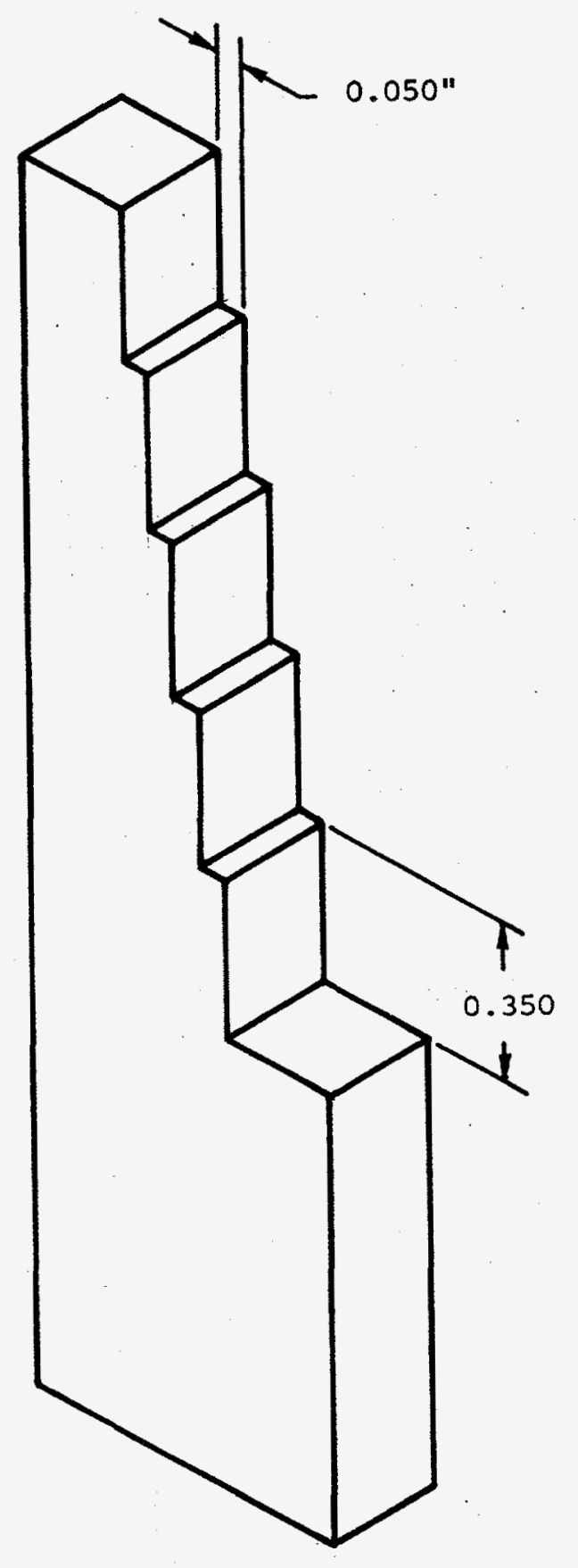

Fig. 1. Type 13 Gage Form

$-4-\cdots$ 


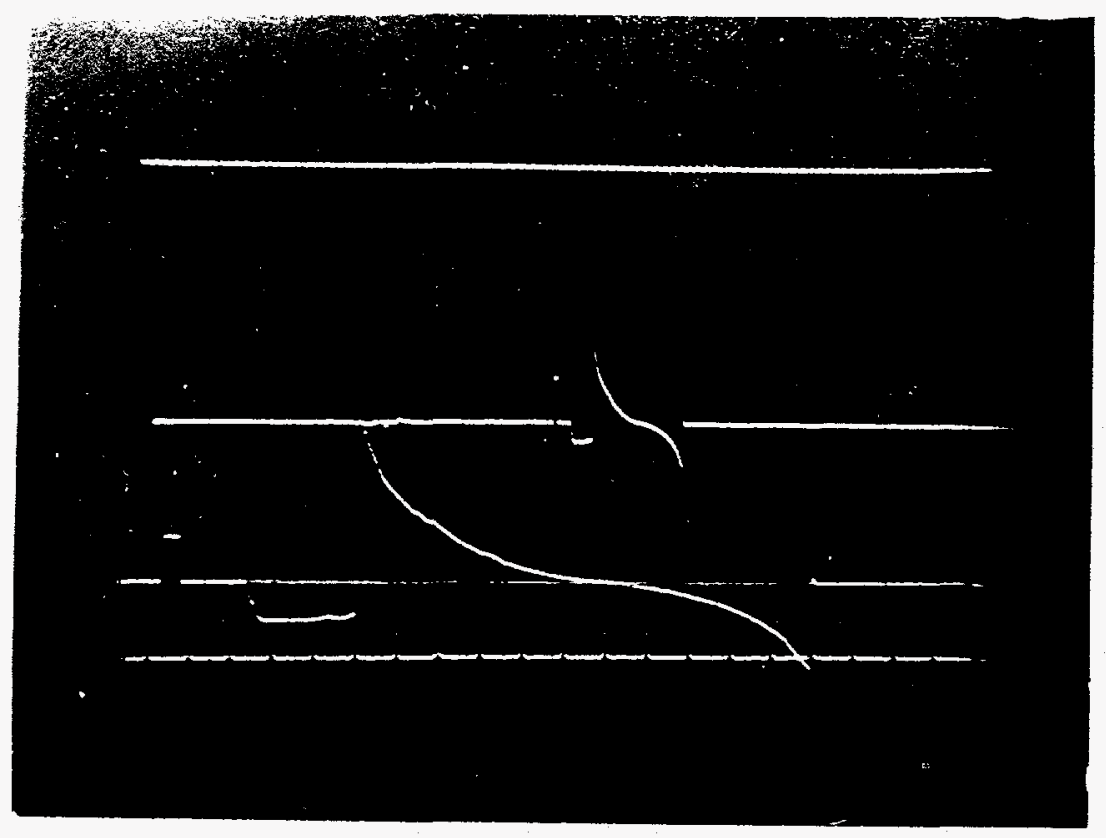

Eig. 2. XMC 2361 Driver. Type 13 Gage. Element at $10.8 \mathrm{~mm} 0.2 \mathrm{v} / \mathrm{cm}, 1.0$ usec/mark (upper) $0.1 \mathrm{v} / \mathrm{cm}, 1.0 \mathrm{isec} / \mathrm{mark}$ (lower)

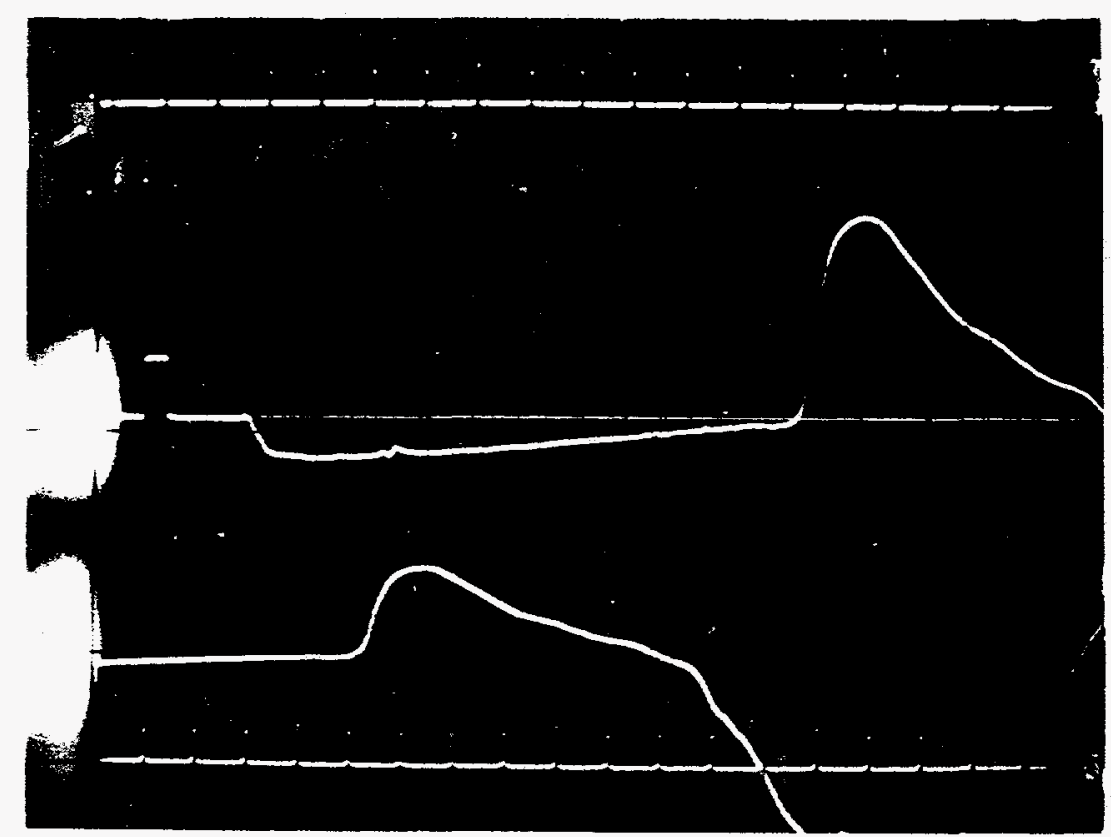

Eig. 3. MC 2361 Driver. Type 13 Gage. Element at $37.1 \mathrm{~mm} 0.02 \mathrm{v} / \mathrm{cm}, 1.0 \mathrm{sec} / \mathrm{mark}$ (upper) $0.05 \mathrm{v} / \mathrm{cm}, 1.0 \mathrm{sec} / \mathrm{mark}$ (lower) 


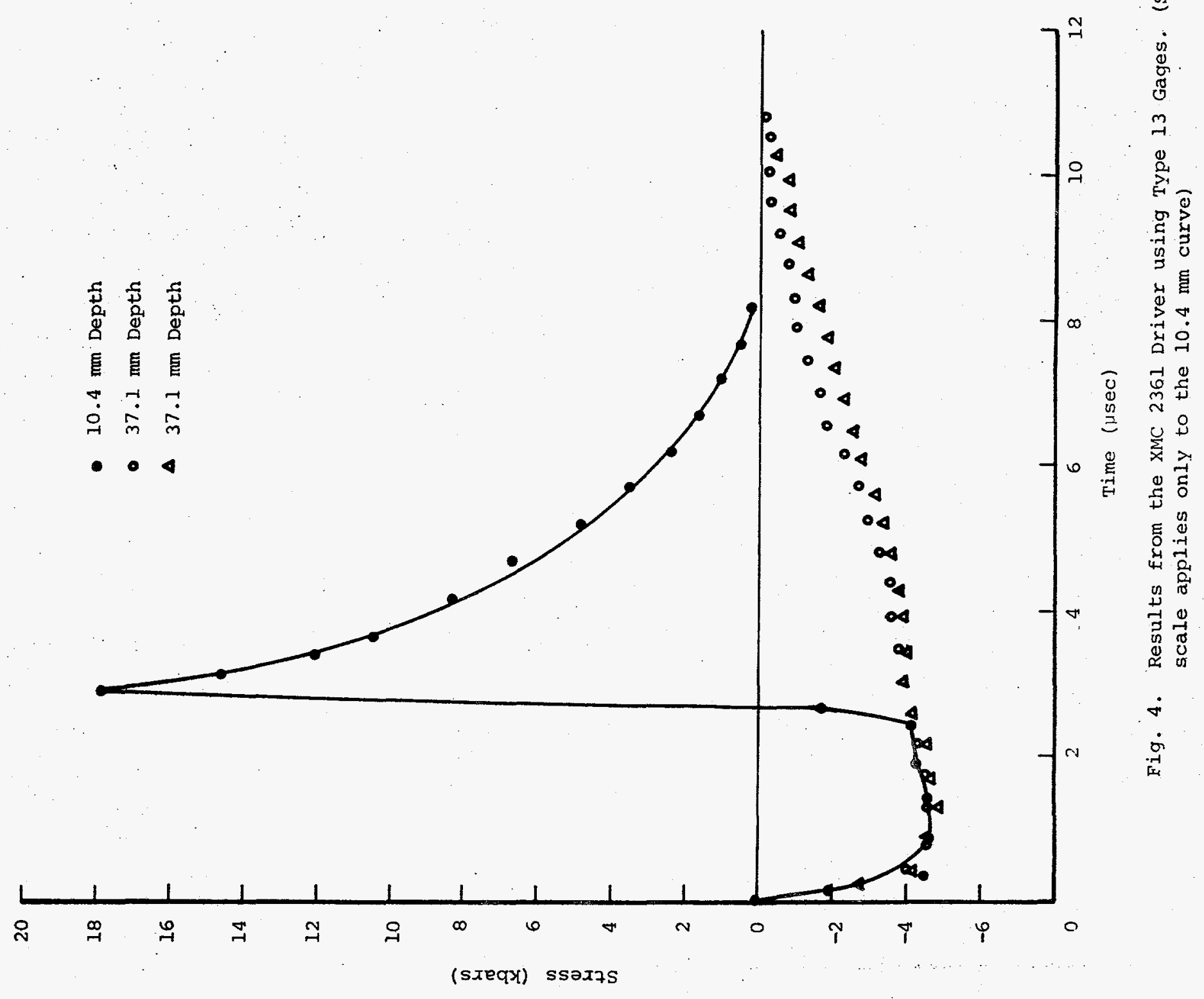




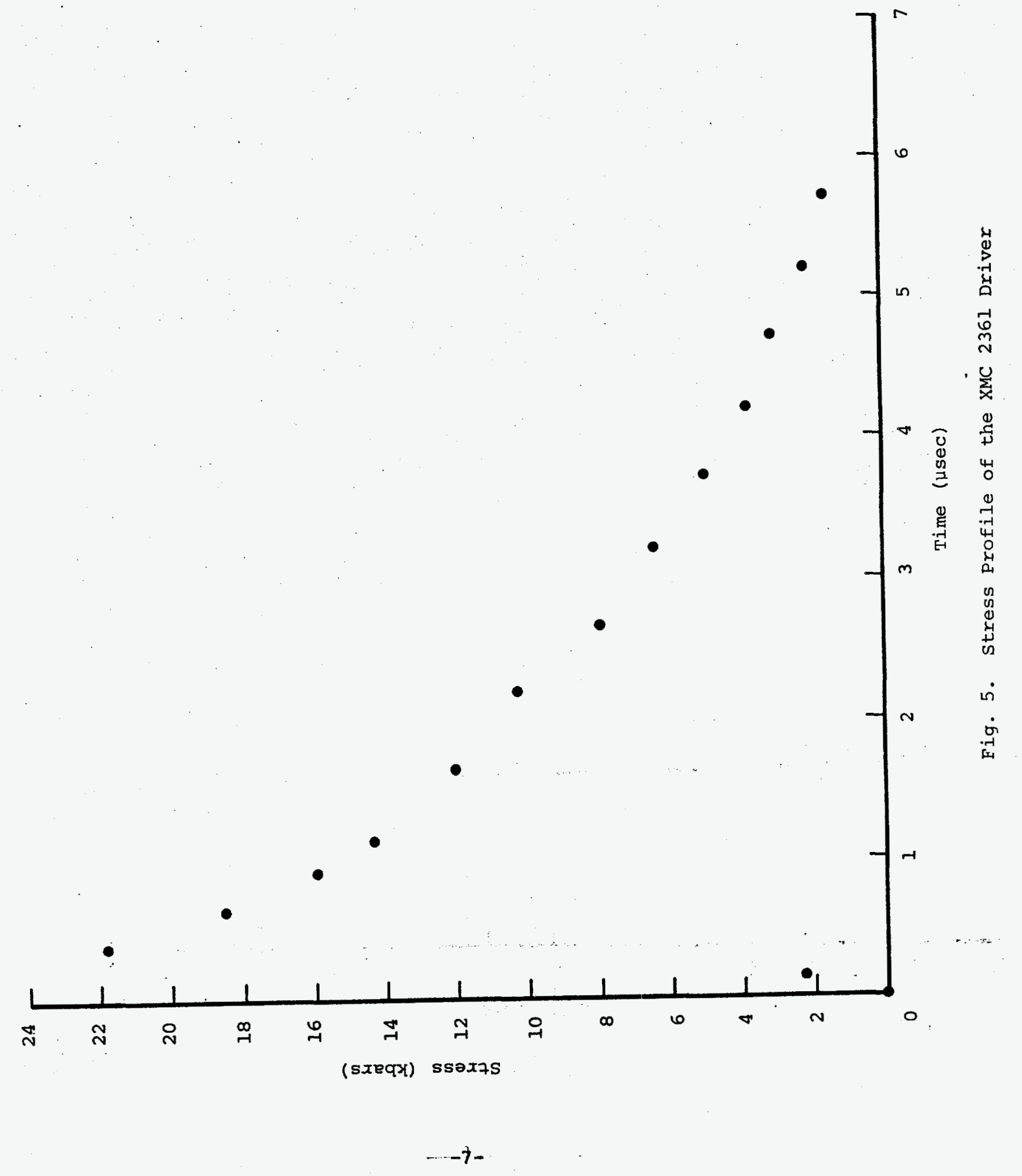




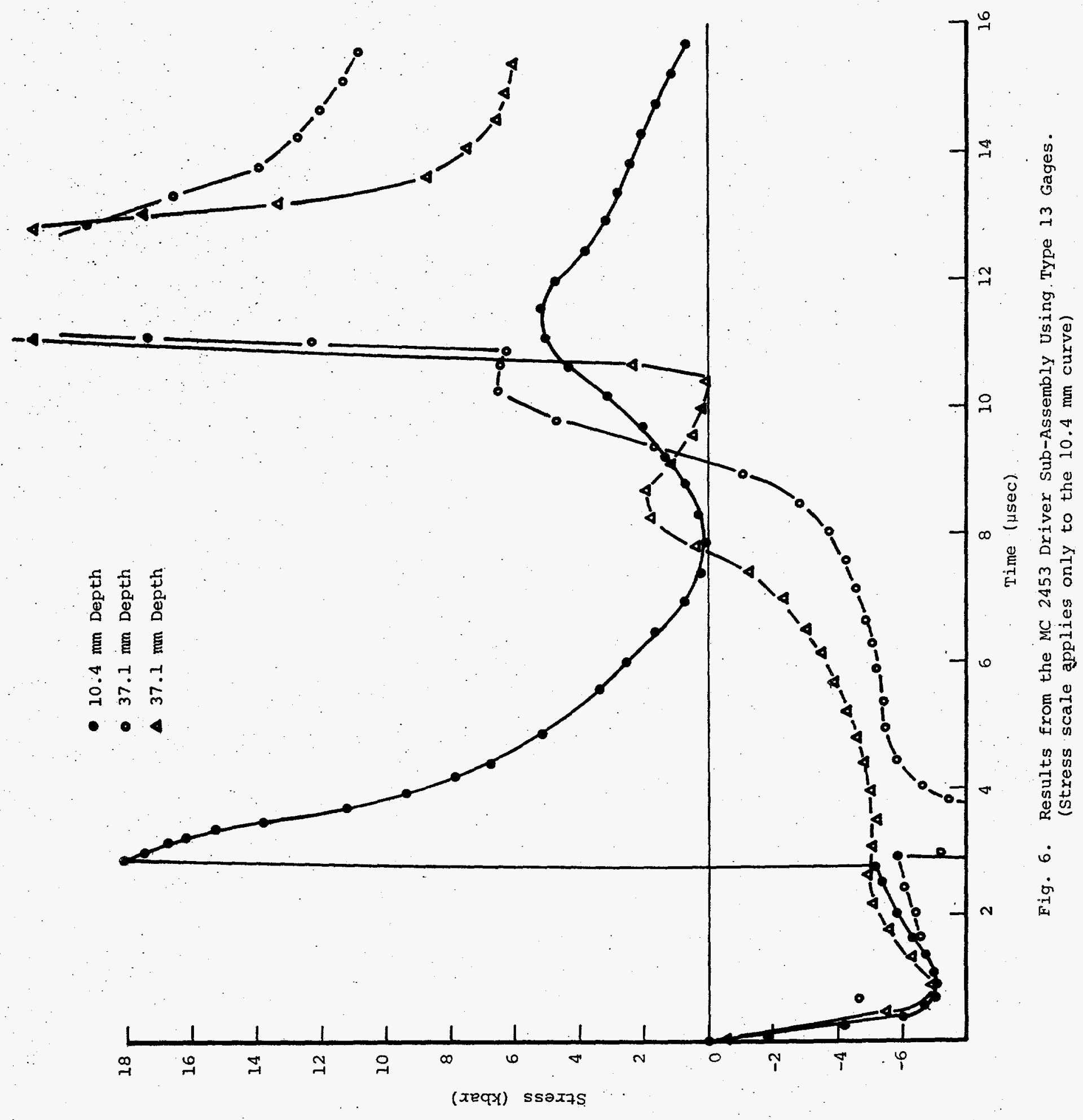




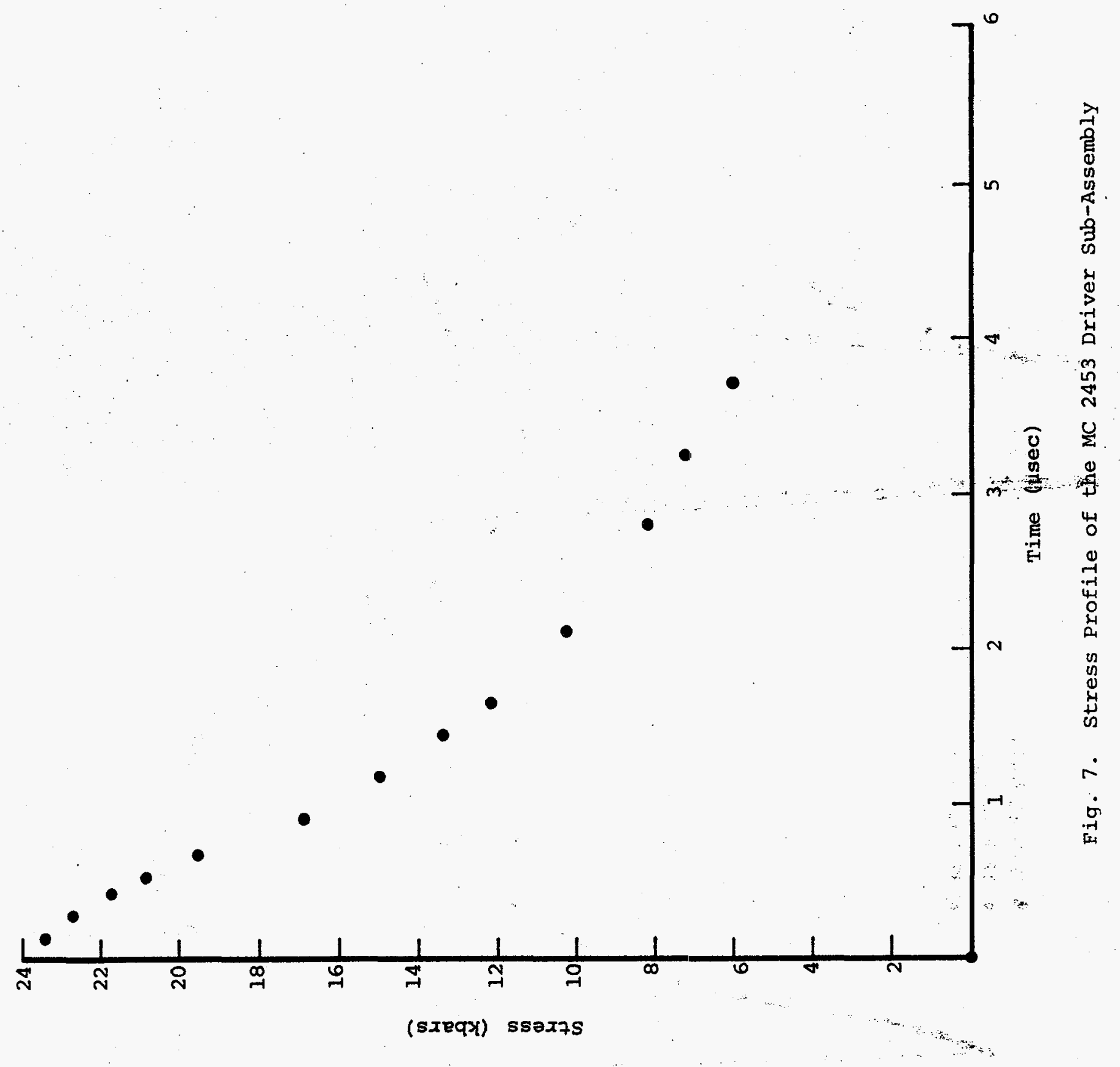




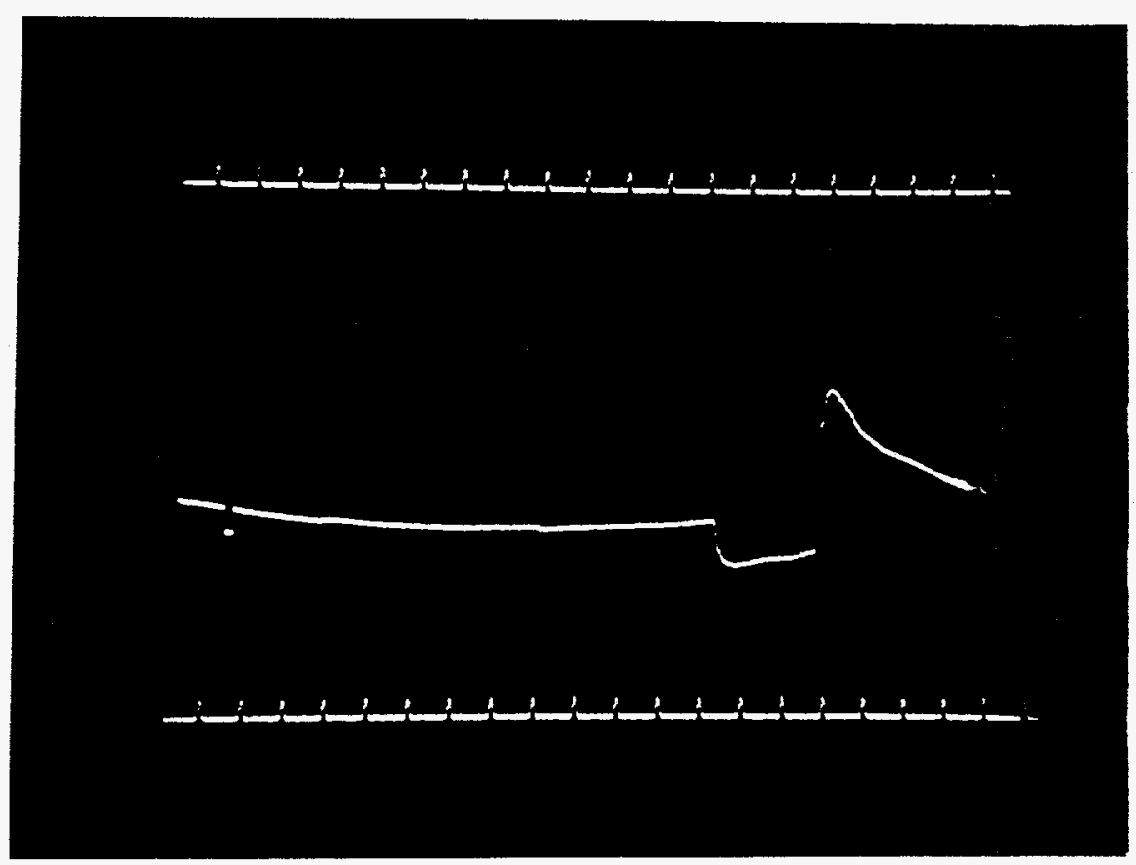

Fig. 8. Flyer plate Timing shot XMC 2361 Driver. $0.1 \mathrm{v} / \mathrm{cm}, 1$ usec/Mark 